\title{
Cleft Rhinoplasty: A Surgical Technique
}

\author{
${ }^{1}$ Vani Mehrotra, ${ }^{2}$ Srivalli Natarajan, ${ }^{3}$ Gaurav Deshpande, ${ }^{4}$ Raj Merchant
}

\begin{abstract}
Nasal deformity, a common occurrence in unilateral and bilateral cleft lip and cleft palate patients, is a formidable challenge for the cleft surgeon. The underlying abnormal anatomy, aggravated by tissue scarring and loss of facial planes after primary procedures, makes secondary rhinoplasty a difficult procedure for even the most experienced. Over the past years, numerous techniques for secondary cleft rhinoplasty have been described in literature. Regardless of the technique adopted, the fundamental goal of cleft rhinoplasty is to achieve a nose that would be esthetically accepted in society as well as functionally accepted by the patient. The correction of nasal deformity can be performed with a closed or an open technique. This article highlights the open technique used for secondary rhinoplasty for a challenging case of unilateral cleft lip nasal deformity in an adult patient.
\end{abstract}

Keywords: Cleft rhinoplasty, Open rhinoplasty, Rhinoplasty, Rhinoplasty technique.

How to cite this article: Mehrotra V, Natarajan S, Deshpande G, Merchant R. Cleft Rhinoplasty: A Surgical Technique. J Contemp Dent 2017;7(3):188-193.

\section{Source of support: Nil}

Conflict of interest: None

\section{INTRODUCTION}

The nose is the most prominent part of the face, and so a properly executed cleft repair directs the beholders' eyes from the deformed lip to the deformed nose. A deformed nose that results from unilateral cleft of the lip and palate is likened to a tent whose one side is depressed. ${ }^{1}$ Surgery for the primary cleft nose presents a major responsibility and challenge, which has a potential magical reward for the infant, family, and surgeon. Achieving an acceptable result is the prime responsibility of the surgeon. The cleft nasal deformity involves the skin, cartilage, mucosa, and skeletal platform. ${ }^{2}$ Theories regarding the origin of cleft nasal deformity have been discussed extensively and continue to be debated until today. The anatomic

\footnotetext{
${ }^{1,4}$ Postgraduate Student, ${ }^{2}$ Professor and Head, ${ }^{3}$ Lecturer

${ }^{1-4}$ Department of Oral and Maxillofacial Surgery, Mahatma Gandhi Mission's Dental College and Hospital, Navi Mumbai Maharashtra, India

Corresponding Author: Vani Mehrotra, Postgraduate Student, Department of Oral and Maxillofacial Surgery Mahatma Gandhi Mission's Dental College and Hospital, Navi Mumbai, Maharashtra, India, Phone: +919594515469, e-mail: vanimehrotra7@gmail.com
}

abnormalities have been measured and documented. The proper understanding of abnormal anatomy in unilateral and bilateral cleft noses is essential in achieving satisfactory esthetic and functional results. ${ }^{3}$

\section{CASE REPORT}

A 23-year-old male with a chief complaint of depressed and asymmetrical nose presented to the Department of Oral and Maxillofacial Surgery. Past medical history revealed that he was operated for cleft lip repair at 3 years of age and palate at 5 years. On extraoral examination of the nose, the septum was deviated toward the noncleft side (Fig. 1). There was short columella, and the columellar base was deviated toward noncleft side. The nasal tip was displaced and the nostrils were asymmetrical. The ala on the cleft side was flared and flattened as compared with the ala on the noncleft side and base of the ala was displaced posteriorly and inferiorly (Fig. 2).

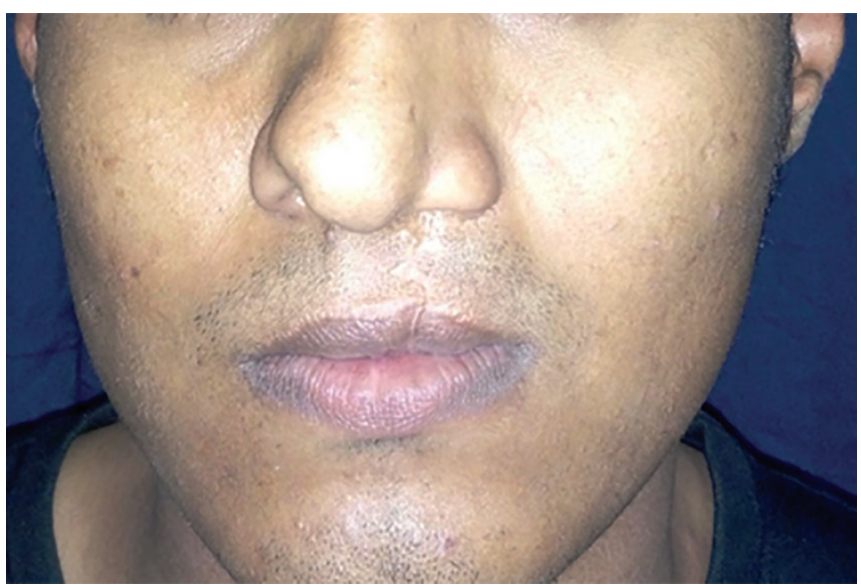

Fig. 1: Clinical picture showing deviated dorsum of nose and ill-defined nasal tip

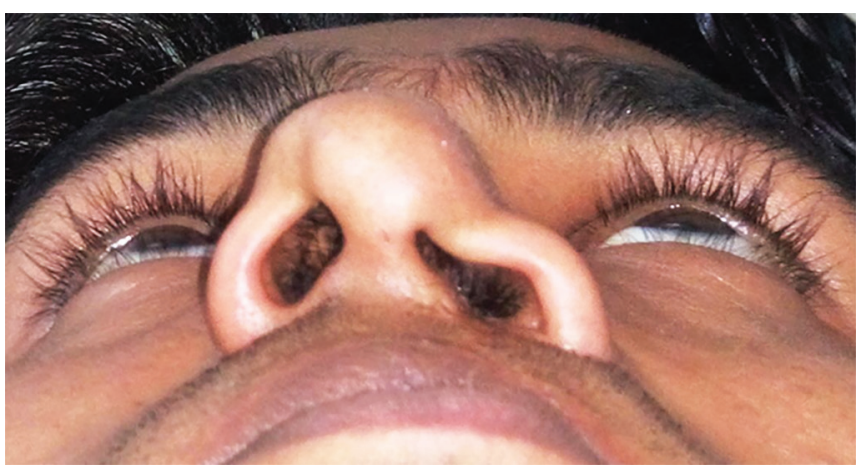

Fig. 2: Clinical picture showing asymmetrical nostril, short columella, and flared ala on cleft side 


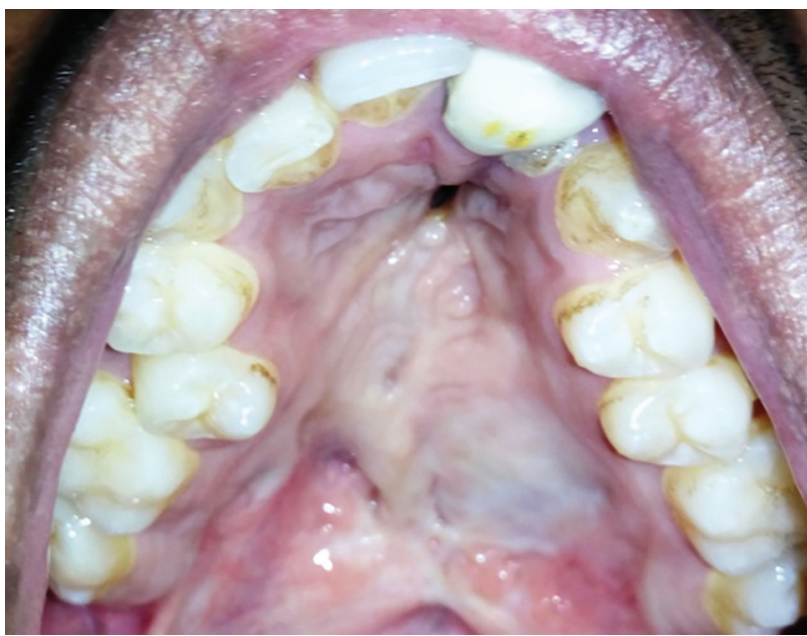

Fig. 3: Clinical picture showing palatal fistula $1 \mathrm{~cm}$ posterior to 21 and absent lateral incisor

Intraoral examination revealed a palatal fistula $1 \mathrm{~cm}$ posterior to 21 (Fig. 3). A second fistula was noted over the buccal vestibule and absent lateral incisor (Fig. 4). Scarring of the palatal tissue was noted suggestive of previous cleft palate repair surgery. There was reverse overjet in the anterior region with crowding in premolar region and class III molars in relation to the left and the right sides.

\section{SURGICAL TECHNIQUE}

A definitive open rhinoplasty was planned for the cleft nasal deformity. The surgery was carried out under general anesthesia via South Pole endotracheal intubation. The entire face and one of the ears were prepped and draped. Oxymetazoline wet ribbon gauze was packed in both the nostrils and bilateral infraorbital nerve block was given using $1 \%$ lignocaine with 1:1,00,000 epinephrine. Local infiltration was given at lateral wall, dorsum, septum, ala, and base of the nose. An inverted " $\mathrm{V}$ " transcolumellar skin incision was made, at the narrowest part of the hourglass-shaped columella. Bilateral marginal incisions or infracartilaginous incisions were made just below the lower part of lower lateral cartilage, and the two incisions were joined. Blunt dissection was carried out without disrupting the footplates of lower lateral cartilage, separating the suspensory ligament.

The anterior septal angle was identified and the perichondrium was scored $3 \mathrm{~mm}$ posterior to the anterior septal angle until the underlying cartilage was exposed. This submucoperichondrial plane was identified by the distinct gray-blue appearance of the cartilage. Bilateral submucoperichondrial tunnels were dissected (Fig. 5), and the upper lateral cartilages were separated from the dorsal septum, releasing the entire quadrangular cartilage until the glabellar region superiorly and until the maxillary crest inferiorly. Then, an incision was

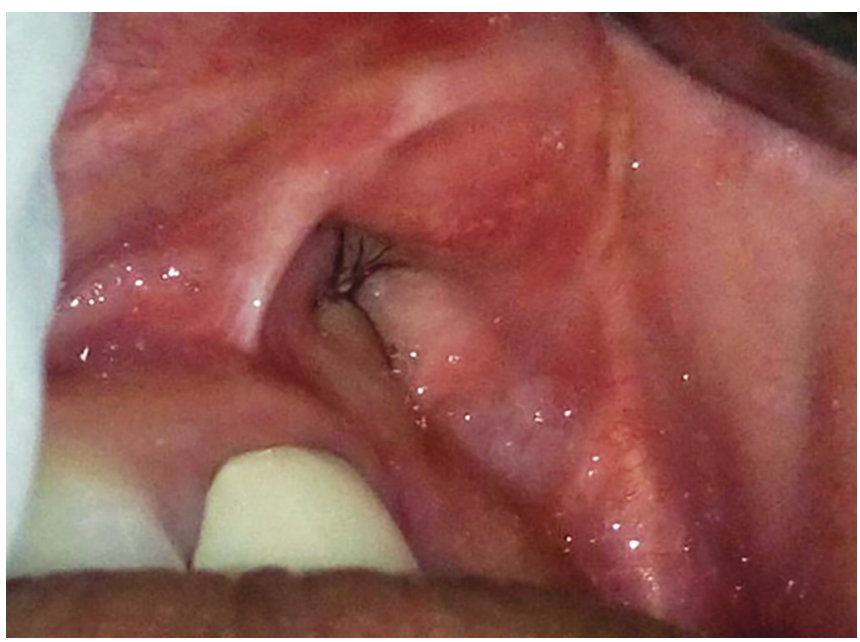

Fig. 4: Clinical picture showing fistula in buccal vestibule

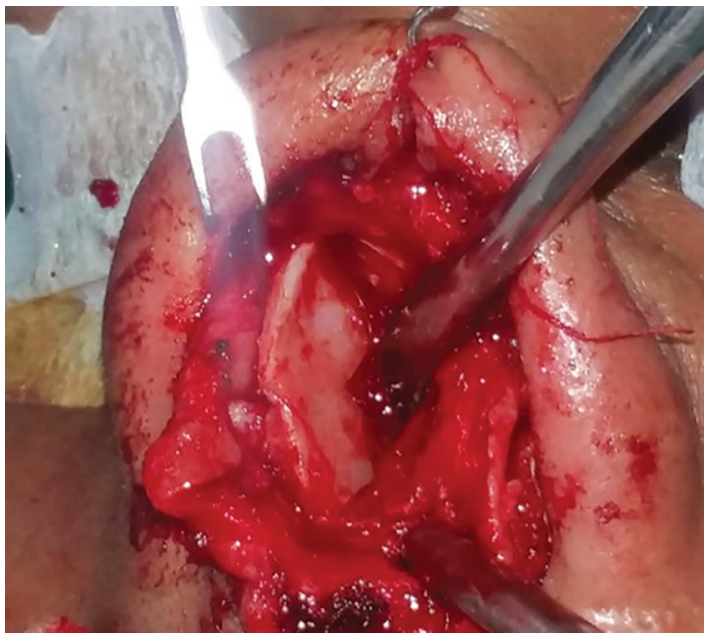

Fig. 5: Intraoperative picture showing subperichondrial dissection

made parallel to the anterior edge of the septum, from the junction of the dorsal L-strut with the perpendicular plate of the ethmoid to the junction of the caudal L-strut with the maxillary crest keeping $1 \mathrm{~cm}$ of nasal septum superiorly and $1 \mathrm{~cm}$ of nasal septum inferiorly. Using a swivel knife, septal cartilage was disarticulated from its position and then elevated using Cottles elevator. This harvested septal cartilage could be used as various grafts for dorsum, radix, ala, and base of the nose. In this case, it was used as columellar strut graft to support the septum and project the tip. To give a proper shape to the tip, an onlay graft was given, which also gave proper contour and support to the ala. To prevent septal hematoma, quilt sutures were given along the septum. Grafts were secured using Vicryl 4-0, and the cartilage was sutured back to the septum using prolene 6-0 (Fig. 6), and skin closure was done using chromic catgut 5-0 (Fig. 7). Nasal packs were given in both the nostrils. Postoperative care included head elevation, and cold compression for the first 48 hours. Strenuous activities and exercise were 


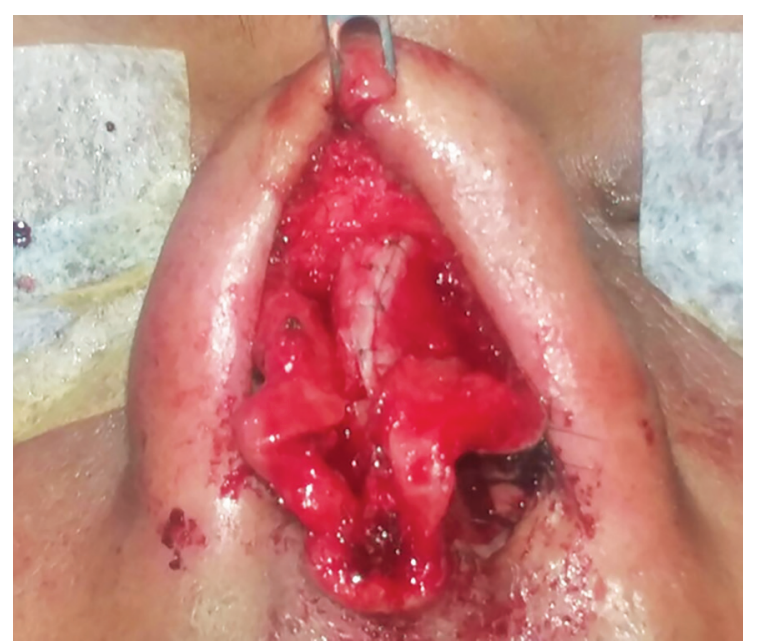

Fig. 6: Intraoperative picture showing mattress sutures given at bilateral lateral cartilage and septum

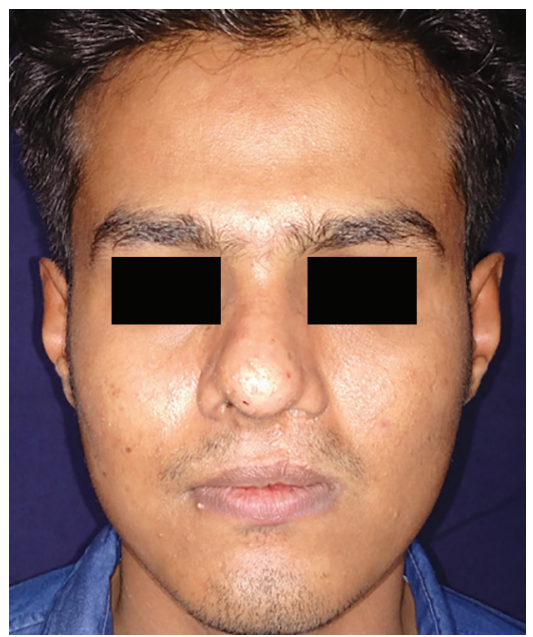

Fig. 8: Clinical picture showing 1 year follow-up

restricted for at least 2 weeks, and heavy lifting of objects was avoided for 4 to 6 weeks after surgery. Patient was advised not to sniff or blow the nose for the first 2 weeks after surgery. Instructions were given to the patient to try not to sneeze, but if it was unavoidable, sneezing through the mouth was allowed without any trauma or pressure on the nose for 6 weeks postoperatively. Patient was followed up for 1 year (Fig. 8).

\section{DISCUSSION}

Blair and Brown ${ }^{4}$ were the first to describe the cleft nose in 1931, critically identifying the nuances of this pathology. The deformity of unilateral cleft nose involves the structural framework of the nose as well as the soft tissue envelope. The aberrant attachment of orbicularis oris muscle insertion results in an imbalance that is further compounded by the maxillary skeletal hypoplasia. ${ }^{5}$ The orbicularis oris muscle inserts in a discontinuous manner into the columella on the noncleft side, rather than

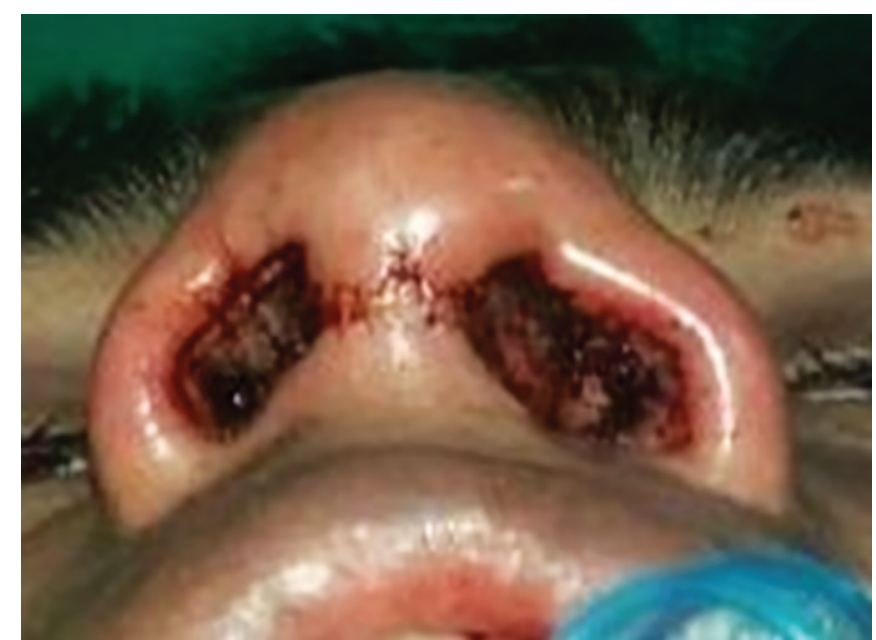

Fig. 7: Immediate postoperative closure showing improved nostril symmetry

horizontal insertion and continuous decussation with the contralateral orbicularis oris as seen in the normal lip. The aberrant attachment creates an unopposed force that pulls the columella and caudal nasal septum to the noncleft side. ${ }^{6}$ On the cleft side, the orbicularis oris muscle inserts into the nasal base, retracting it laterally and inferiorly. In addition to it, due to poor maxillary skeletal support at the alar base, the ala is further displaced posteriorly. The goals of definitive rhinoplasty include creation of nasal symmetry, definition of nasal base and tip, relief of nasal obstruction, if any, and management of nasal scarring. According to timing of surgery, cleft rhinoplasty can be classified as primary, intermediate, and secondary repair. Previously, it was believed that the early manipulation of the nasal cartilage interferes with the growth, but now multiple studies have disproved this belief. ${ }^{7} \mathrm{McC}$ Comb and Coghlan overturned the philosophy that the large submucous resections of the nasal septum affect subsequent nasal and midface growth, by demonstrating in an experimental study that repositioning of the lower lateral cartilage without cartilage resection did not interfere with subsequent nasal and midfacial development. ${ }^{8}$

Because of these findings, primary cleft rhinoplasty is done by the cleft surgeon at the time of initial cleft lip repair itself. ${ }^{9}$ This early intervention benefits the surgeon for an earlier restoration of nasal shape with the potential for more symmetric nasal growth. It is important to note that any surgery done at an early age will subsequently result in scar tissue and consequently affect future surgeries. Intermediate rhinoplasty is usually performed before the cleft patient enters school, between the age of 4 and 6 years. ${ }^{10}$ This allows the surgeon to perform any minor lip revisions, if necessary, as well as achieve better nasal tip symmetry. 
Secondary rhinoplasty occurs after facial growth is completed. This is around 14 to 16 years of age in female patients and 16 to 18 years of age in male patients. ${ }^{11}$ Surgical techniques followed rely on the well-accepted rhinoplasty principles and are applied for unilateral or bilateral cleft nasal deformities. ${ }^{12}$ Rhinoplasty can be done either by a closed technique or an open technique. The difference between the two techniques is if the incision is taken over the columella, it is an open technique, and, if not, it is a closed technique. Since the incision is taken over the columella, the open approach is preferred for better exposure and visualization. It is a good teaching tool and yields manipulation of the nasal elements. Placement of grafts for support and reinforcement is a major component of the cleft rhinoplasty operation. Use of cartilage grafts reinforces the structural support of the nose, allowing for better tip definition, and preventing wound contracture and collapse. Some surgeons also use autologous osseous grafts like calvarial or rib graft, or alloplastic osseous grafts for better bony support. There are various incisions that can be used in open and closed rhinoplasty like columellar, Kilian, transfixion, hemitransfixion, sill incision, wedge, rim, and marginal incisions. Columellar incision is made midway between the nostril and base of the columella, at the narrowest part along the length of columella (Fig. 9). ${ }^{2}$ Kilian incision is

Table 1: Various grafts according to anatomic description

\begin{tabular}{ll}
\hline Dorsum & Autospreader flap \\
& Dorsal onlay graft \\
& Dorsal sidewall onlay graft (lateral nasal wall \\
& graft) \\
& Radix graft \\
& Spreader grafts \\
& Septal extension graft \\
& Anchor graft \\
Tip & Cap graft \\
& Columellar strut graft (fixed) \\
& Columellar strut graft (floating/fixed floating) \\
& Extended columellar strut-tip graft (extended \\
& shield graft) \\
& Onlay tip graft \\
& Shield graft (Sheen or infralobular graft) \\
& Subdomal graft \\
& Umbrella graft \\
& Alar batten graft \\
& Alar contour graft (alar rim graft) \\
& Alar spreader graft (lateral crural spanning graft) \\
Composite alar rim graft \\
Lateral crural onlay graft \\
Lateral crural strut graft \\
Lateral crural turnover graft \\
Alar base graft \\
Columellar plumping grafts \\
Premaxillary graft \\
\hline
\end{tabular}

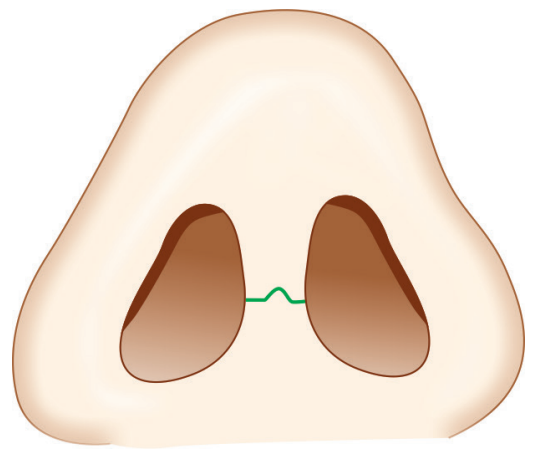

Fig. 9: Diagrammatic picture showing columellar incision

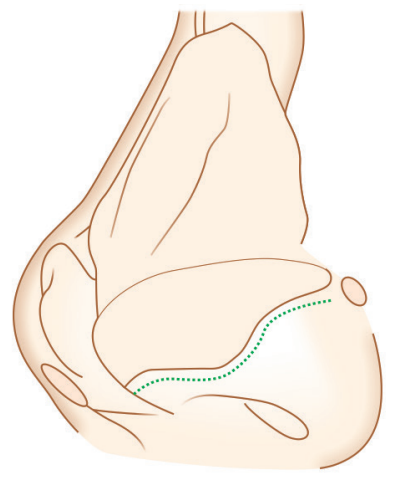

Fig. 10: Diagrammatic picture showing marginal incision

taken to approach the nasal septum, where an incision is made 1 to $2 \mathrm{~cm}$ posterior (behind) the caudal edge of the cartilaginous septum. Kilian incision is considered to be less disruptive to the nasal tip support-mechanism structures. Wedge incision is made between the nose and cheek region to narrow an alar base. Intercartilaginous incision is made at the junction of the upper lateral cartilage and the lower lateral cartilage. Sill incision is a nonspecific term used to describe an incision that narrows the alar base. Rim incision is an incision made along the rim of the nostril, and marginal incision is an incision made at the caudal (lower) end of the lower lateral cartilage (Fig. 10). In this surgical technique, the incisions used were transcolumellar and infracartilaginous or marginal incision bilaterally.

There are various grafts that can be used to achieve proper esthetics and function of nose (Table 1). Grafts with the help of the Gunter Rhinoplasty Diagrams (Fig. 11) are described and listed according to their intended location on the nose, and in alphabetical order within each group. The shapes, position, and usage of grafts vary depending on the situation and the desire of the surgeon. According to their intended use and anatomical location, grafts can be classified as dorsum, radix, ala, and base. In this surgical technique, the grafts used were columellar strut, onlay tip, and alar base graft. The grafts can be harvested from nasal septal cartilage, auricular cartilage, or rib cartilage. The most commonly used is septal cartilage, 

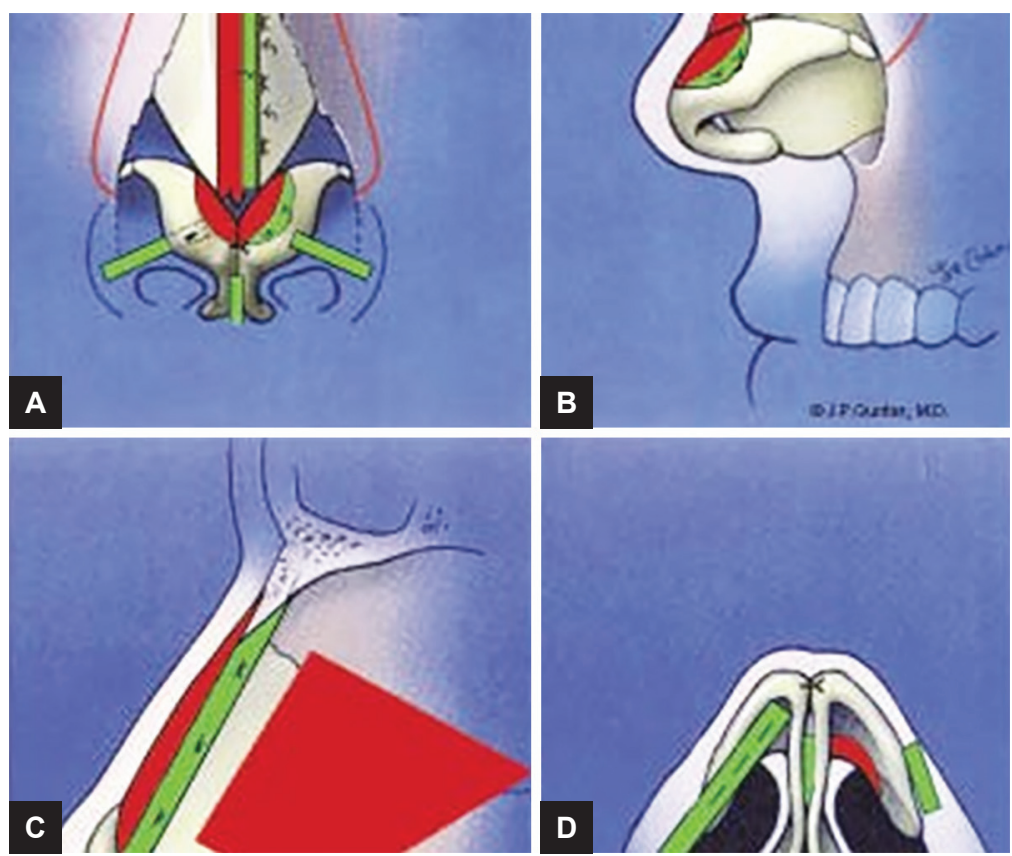

Figs 11A to D: Gunter Diagram System showing color coding. Green: autologous grafts, black: sutures and outline of anatomic structures, red: incisions and excisions, orange: previous incisions or excisions, blue: implants

as it can be harvested from the same area and there is no second surgical site that automatically cuts off the duration of surgery. The only problem with septal cartilage is septal hematoma and, sometimes, the septum itself is rudimentary in severe cleft cases. With rib cartilage, there are chances of pneumothorax and also a second surgical site. Also being costochondral cartilage, it has a tendency to warp and it grows continuously, which can pose a problem later. Given the flaccidity and the convolutions inherent to auricular cartilage, it is ideal for reconstructing the lower lateral cartilages. Demerits are second surgical site and auricular hematoma. In this technique, nasal septal cartilage was used as grafts, as the amount of graft required was less, and it could be harvested from the same surgical site.

\section{CONCLUSION}

The primary concern of patients having cleft nasal deformity is unesthetic appearance, along with a constant psychological fear of being unaccepted by the society. The primary goal of rhinoplasty procedure is to restore normal form and function, thereby restoring symmetry and repositioning the nasal structures, so that further growth will not exacerbate the deformities. Cleft nasal deformity is a complicated problem that should be addressed during multiple stages of the patient's life. The cleft nasal deformity will continue to remain a challenge to the surgeons, as it requires a thorough and detailed understanding of the anatomy of cleft pathology, and accurate assessment of both esthetic and functional impairments.

\section{ACKNOWLEDGMENT}

All the surgeries at Maaya Cleft and Craniofacial Unit at Mahatma Gandhi Mission's Dental College and Hospital were possible due to generous funding by Inga Health Foundation, Operation Smile Inc, Tata Trust, HDFC Credila and other donors. Authors heartfully acknowledge their contribution.

\section{REFERENCES}

1. Baskaran M, Packiaraj I, Arularasan SG, Divakar TK. Cleft rhinoplasty. J Pharm Bioallied Sci 2015 Aug;7(Suppl 2): S691-S694.

2. Pawar SS, Wang TD (2014) Secondary cleft rhinoplasty. JAMA Facial Plast Surg 2014 Jan-Feb;16(1):58-63.

3. Kaufman Y. Cleft nasal deformity and rhinoplasty. Semin Plast Surg 2012 Nov;26(4):184-190.

4. Blair V, Brown JB. Nasal abnormalities, fancied and real. Surg Gynecol Obstet 1931;53:797-819.

5. Rifley W, Thaller SR. The residual cleft lip nasal deformity. An anatomic approach. Clin Plast Surg 1996 Jan;23(1): 81-92.

6. Fisher DM, Sommerlad BC. Cleft lip, cleft palate, and velopharyngeal insufficiency. Plast Reconstr Surg 2011 Oct;128(4):342e-360e.

7. McComb H. Primary correction of unilateral cleft lip nasal deformity: a 10-year review. Plast Reconstr Surg 1985 Jun;75(6):791-799.

8. McComb HK, Coghlan BA. Primary repair of the unilateral cleft lip nose: completion of a longitudinal study. Cleft Palate Craniofac J 1996 Jan;33(1):23-30, discussion 30-31.

9. Morovic CG, Cutting C. Combining the Cutting and Mulliken methods for primary repair of the bilateral cleft lip nose. 
Plast Reconstr Surg 2005 Nov;116(6):1613-1619, discussion 1620-1622.

10. Shih CW, Sykes JM. Correction of the cleft-lip nasal deformity. Facial Plast Surg 2002 Nov;18(4):253-262.

11. Kohout MP, Aljaro LM, Farkas LG, Mulliken JB. Photogrammetric comparison of two methods for synchronous repair of bilateral cleft lip and nasal deformity. Plast Reconstr Surg 1998 Oct;102(5):1339-1349.

12. StalS, Brown RH,HigueraS, Hollier LHJr, Byrd HS, Cutting CB, Mulliken JB. Fifty years of the Millard rotation-advancement: looking back and moving forward. Plast Reconstr Surg 2009 Apr;123(4):1364-1377. 